\title{
The pyrolysis and gasification of high density polyethylene in a batch reactor
}

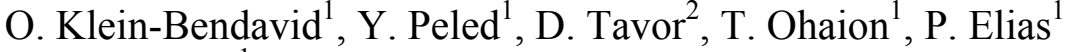 \\ \& G. Bar-Nes ${ }^{1}$ \\ ${ }^{1}$ Negev Nuclear Research Center, Israel \\ ${ }^{2}$ Department of Chemical Engineering, \\ Sami Shamoon College of Engineering, Israel
}

\begin{abstract}
Solid organic waste contaminated with radionuclides is a challenging wasteform in its raw state. NRCN, as the national repository for radioactive waste in Israel, accepts all such waste from industry, hospitals, universities and from the Israeli nuclear research centers. Organic waste is characterized by its high volume to weight ratio, together with the hazard of its radiolysis and consequently, the generation of combustible and explosive gases (e.g. H2 and light hydrocarbons). Thus, minimizing waste volumes together with stabilizing the wasteform are of high significance in the treatment of contaminated polymers. In this study, the thermal decomposition process is aimed at maximizing the room temperature gas yield, and minimizing the oil and wax fraction that will be harder to entrain in a large scale system.
\end{abstract}

High density polyethylene (HDPE) is a thermoplastic polyolefin characterized by its high strength and diverse utilities. In the current research, we investigated the thermal decomposition of HDPE using thermogravimetric analysis (TGA) at the milligram scale; whereas a laboratory scale thermal decomposition system was utilized for experiments at the gram scale. The TGA method enables the study of the thermal decomposition parameters, whereas the macro-scale experimental system enables the study of the decomposition products (e.g. char, wax, oil and gas).

Polymer decomposition was studied under variable atmospheres, ranging from pure pyrolysis, under a nitrogen atmosphere, to gasification under $88 \%$ nitrogen and $12 \%$ oxygen atmosphere in the macro-scale system (with a similar total gas flow rate). Only pyrolytic conditions were applied in the TGA 
experiments. Decomposition temperatures ranged between 450 and $600^{\circ} \mathrm{C}$ for HDPE in the macro-scale system. TGA experiments focused on narrower temperature scale between 420 and $480^{\circ} \mathrm{C}$.

An exponential increase in the decomposition rate of HDPE was detected with the increase in the experimental temperature in the TGA experiments. The rate of decomposition at $420^{\circ} \mathrm{C}$ was $0.79 \pm 0.074 \% / \mathrm{min}$; this value has increased by two orders of magnitude to $49.71 \pm 1.1 \% / \mathrm{min}$ at $480^{\circ} \mathrm{C}$. The activation energy calculated using the Arrhenius equations is $298 \mathrm{KJ} / \mathrm{mol}$.

In the macro-scale system, at $450^{\circ} \mathrm{C}$, under pyrolytic conditions, only $22 \%$ of the raw material was converted to gas; the remaining mass was converted to wax and oil with only minor formation of char. On the other hand experiments conducted at 525 and $600^{\circ} \mathrm{C}$ yielded similar amounts of gas and oil, where $63-65 \%$ of the experimental charge were converted to gas, $27-29 \%$ condensed as wax at temperatures higher then $180^{\circ} \mathrm{C}$ and only $5-7 \%$ condensed as oil and wax at lower temperature.

The formation of over $30 \%$ of wax and oil is expected to be problematic in the operation of a large scale decomposition system. Thus, thermal decomposition of HDPE was attempted under gasification conditions with 3, 7 and $12 \%$ of $\mathrm{O}_{2}$ in the atmosphere. The experiments were conducted at $525^{\circ} \mathrm{C}$. The proportion of produced gas ranged between $54 \%$ at $3 \% \mathrm{O}_{2}$ up to $61 \%$ with $12 \%$ of $\mathrm{O}_{2}$ in the atmosphere. None of the oxidized environments have produced more gas compared to the pyrolytic conditions, whereas an increase in the fraction of the low condensation temperature gases was noted. To conclude, neither pyrolysis nor gasification leads to high enough gas fraction at room temperature to be considered as a single state thermal treatment for contaminated solid organic material.

Keywords: pyrolysis, gasification, high density polyethylene, batch reactor.

\section{Introduction}

The Israeli national radioactive waste disposal site is situated at the Nuclear Research Center Negev (NRCN). Radioactive waste from hospitals, research institutions and industry is delivered to the site. Waste disposal sites are limited in their capacity, thus, volume reduction of the waste form is of high significance to the site operative future. Additionally, hydrocarbon based polymers go through degradation in the presence of radioactive radiation. Such degradation may cause the formation of combustable and explosive gases such as hydrogen. Thus, the chemical stabilization of the wasteform is also of high importance for the site's safety. As such environmental concerns are becoming of high importance in the long term operation of radioactive waste sites, robust treatment strategy of plastic wastes and especially radioactive waste are considered important.

Pyrolysis is the thermochemical decomposition process of organic materials in the absence of oxygen to produce char, hydrocarbon oil and wax and gases such as hydrocarbons and hydrogen. Gasification is defined as the thermal, non combustion, decomposition of organic material with a limited amount of oxygen 
and/or steam. Both processes are considered today as advanced thermal treatment technologies leading to mass and volume reduction of radioactive/hazardous organic waste, while retaining the radionuclides and inorganic material in solid form to be further disposed.

Like incineration, pyrolysis reduces the waste volume by tens of percents, and concentrates the associated inorganic substances, in the char. The main industrial advantages of pyrolysis over incineration are in its ability to recycle valuable raw material such as hydrogen, methane, and aromatic substances. Furthermore, the fact that the pyrolysis process is endothermic makes it easier to control and manipulate. Pyrolysis is a more environmentally friendly process compared to incineration, with considerably lower toxic gas emissions [1, 2], and its products can serve as fuel for its on-going operation.

Unlike incineration which is highly versatile in its ability to process numerous waste forms, pyrolysis is sensitive to the chemical composition of the raw polymer treated and thus, the product distribution will depend heavily on it. Additionally, the products obtained will depend on the process temperature, as well as on the characteristics of the reactor used in the process [e.g. 3].

Gasification, is facilitated using limited oxygen/steam availability, its main products are hydrogen and $\mathrm{CO}$, which are important raw materials in various synthetic processes. The main disadvantages of this process are the formation of larger amounts of airborne particulate matter, and its high energy costs [2].

The universal use of pyrolysis/gasification as a leading waste treatment process is in its primary industrial stages. Mostly, due to the industrial complications in processing mixed wastes (e.g. different plastic polymers), and to the relatively low cost of landfill disposal and incineration in most countries. Nevertheless, active industrial pyrolysis/gasification facilities are active in North America [4] Germany and Japan [5], while at other locations worldwide the technology is in the state of development $[5,6]$.

The treatment of radioactively contaminated polymer waste has been considered around the world at laboratory and pilot plant scales. The main goal in this treatment in the reduction of waste volume, and the concentration of the radioactive waste in the solid product, that can be safely transferred and disposed to a regulated radioactive waste site [7].

The present study investigates the thermal decomposition of High Density Polyethylene (HDPE). HDPE, is a thermoplastic polymer, it has a high strength to density ratio with high densities ranging between 0.93 and $0.97 \mathrm{~g} / \mathrm{cm}^{3}$. Its melting point is at $127-135^{\circ} \mathrm{C}$. It is characterized by the large number of linear, unbranched ethylene chains, with high crystallinity. HDPE is commonly used in the production of bottles, piping, membranes, and other products.

The thermal decomposition of HDPE, consists of an initiation step, including the homolytic breakdown of the polymer chain and the formation of two radicals [8].

$$
\mathrm{R}^{\prime}-\left(\mathrm{CH}_{2}\right)_{4}-\mathrm{CH}_{2}-\mathrm{R}^{\prime \prime} \rightarrow \mathrm{R}^{\prime}-\left(\mathrm{CH}_{2}\right)_{4}-\mathrm{CH}_{2}+\mathrm{R}^{\prime \prime}
$$

In the propagation stage $\beta$-scission is the dominant process. 


$$
\mathrm{R}^{\prime}-(\mathrm{CH} 2) 4-\mathrm{CH} 2 \rightarrow \mathrm{R}^{\prime}-(\mathrm{CH} 2) 2-\mathrm{CH} 2+\mathrm{CH} 2=\mathrm{CH} 2
$$

Thereafter dienes and alkanes can be formed, where the formation of alkanes is favoured due to intermolecular hydrogen transfer reaction:

$$
\begin{gathered}
\text { R'-(CH2)4-CH2 + R'-(CH2)2-CH2-R" } \rightarrow \\
\text { R'-(CH2)4-CH3 + R'-CH2-CH-CH2-R" }
\end{gathered}
$$

The process can be terminated by recombination of the products:

$$
\mathrm{R}^{\prime} \cdot+\mathrm{R} \prime \cdot \rightarrow \mathrm{R}^{\prime}-\mathrm{R}^{\prime \prime}
$$

Within this study HDPE decomposition was investigated by combining two experimental systems Thermo-Gravimetric Analysis (TGA) was used to measure the maximal decomposition rates at different pyrolytic experimental conditions at the milligram scale and to obtain the activation energy of the decomposition reaction. Product distribution and the extent of conversion to gas under pyrolytic and partial oxidizing conditions (gasification) have been obtained from experiments performed in the pyrolysis/gasification system at the milligram scale.

\section{Methods}

\subsection{Raw materials}

The raw material used for the experiments was a HDPE pipe of "Metzerplas" company (water (HDPE) PE 100, 32X3.0, PN 16) grounded to $5 \mathrm{~mm}$ particles.

\subsection{Experimental systems}

\subsubsection{Thermo-gravimetric analysis (TGA)}

TGA analysis was performed using a Mettler-Toledo TGA/SDTA851 ${ }^{\mathrm{e}} .5 \mathrm{mg}$ samples were weighted into alumina crucibles. The samples were heated at $20^{\circ} \mathrm{C} / \mathrm{min}$ to the set point temperature and then kept at an isotherm. Carrier gas was circulated through the system at a designated flow rate. Data reduction was performed using the $\mathrm{STAR}^{\mathrm{e}}$ software. The temperature accuracy is $\pm 0.5^{\circ} \mathrm{C}$ and the weighting accuracy is \pm 1 microgram. Experiments were run at 420, 435, 450 and $480^{\circ} \mathrm{C}$ with gas discharges of $20,70,120$ and $170 \mathrm{ml} / \mathrm{min}$. Duplicates were run for each experiment. Only inert atmosphere experiments were conducted using this system.

\subsubsection{Laboratory scale thermal decomposition system}

The thermal decomposition system is composed of a tubular oven, $40 \mathrm{~cm}$ in length and $8 \mathrm{~cm}$ in diameter (figure 1). A tube shaped quartz reactor $(42 \mathrm{~mm}$ in diameter) in which the thermal decomposition process takes place is inserted into the oven. Carrier gas is inserted into the reactor from its entrance, through an alumina pipe, using a mass flow controller. Temperature is monitored by a 
$\mathrm{K}$ type thermocouple set in an alumina tube. Decomposition products are accumulated in two glass traps, at $180^{\circ} \mathrm{C}$ and $5^{\circ} \mathrm{C}$, which enable the entrapment and separation of oily products at both elevated and low temperatures. Room temperature gas products are sampled via a TEDLER bag (SKC company) sampling system. The thermal decomposition system is assembled in a flow hood to prevent hazardous gas leak into the room. In the current study, experiments were run at 450,525 and $600^{\circ} \mathrm{C}$. It should be noted that due to the large gradient between the oven and the surrounding environment the temperature measured in the hottest point in the oven was higher by $10 \%$ relative to the set point temperature, thus, the thermal decomposition products have experienced higher temperatures than the raw material.

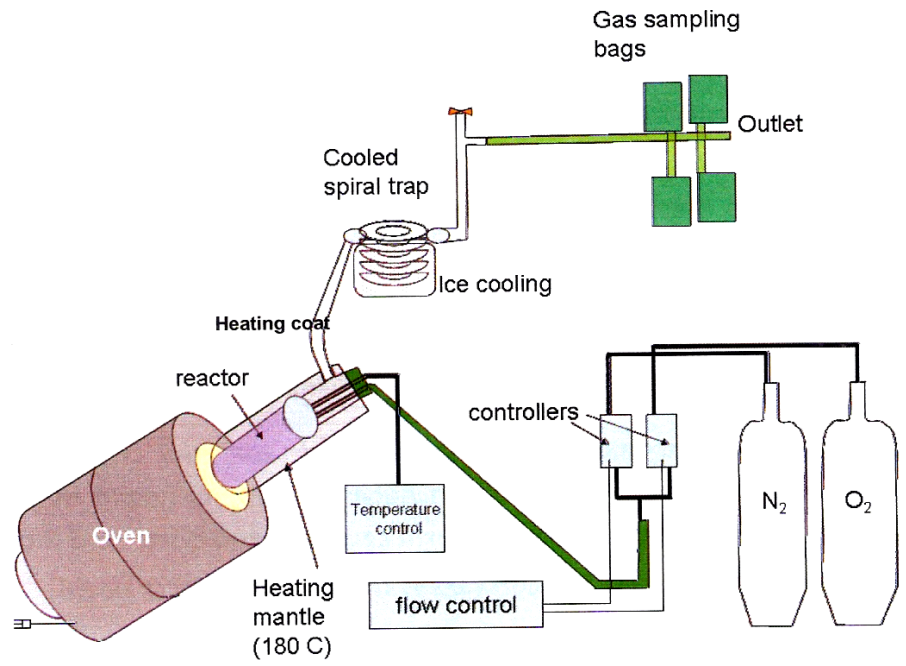

Figure 1: Lab-scale thermal decomposition system.

The carrier gas consisted of analytical grade oxygen and nitrogen mixtures. The gas flow in all of the experiments was set to $20 \mathrm{ml} / \mathrm{min}$ by the mass flow controller and the gas composition varied between 1) $\left.100 \% \mathrm{~N}_{2} ; 2\right) 97 \% \mathrm{~N}_{2}$ and $3 \% \mathrm{O}_{2}$; 3) $93 \% \mathrm{~N}_{2}$ and $7 \% \mathrm{O}_{2}$; 4) $88 \% \mathrm{~N}_{2}$ and $12 \% \mathrm{O}_{2}$. The nitrogen atmosphere enables pyrolytic conditions and the oxygenated atmospheres enable various degrees of gasification. All of the experimental assemblage was weighted prior to the experiment. The pre-weighted system parts were reweighed after the experiment for mass balance calculations. The combined experimental error was estimated as $10 \%$. Wax and oil samples were collected from the reactor, the hot and the cold trap after the experiment. 


\section{Results}

\subsection{TGA experiments}

\subsubsection{Inert gas flow rate effect on the thermal decomposition process}

Isothermal experiments were performed at different gas discharge (e.g. 20, 70, 120 and $170 \mathrm{ml} / \mathrm{min}$ ). Figure $2 \mathrm{a}$ shows the TGA and DTG (differential thermal gravimetric) analysis of the experiments at $450^{\circ} \mathrm{C}$. Small differences in the decomposition rate between the different experiments were found resulting mainly from the cooling effect of the inert gas flow. Similar results were collected for the experiment at 420,435 and $480^{\circ} \mathrm{C}$.

\subsubsection{Temperature effect on the thermal decomposition process}

Experiments were performed at a constant gas discharge of $20 \mathrm{ml} / \mathrm{min}$, at the designated experimental temperature (e.g. 420, 435, 450, $480^{\circ} \mathrm{C}$ ). Figure $2 \mathrm{~b}$ shows the TGA and DTG curve of the experiments.

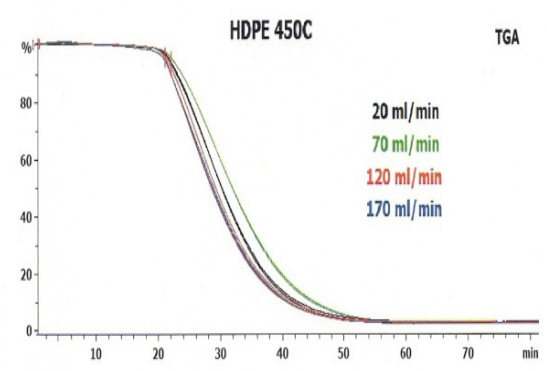

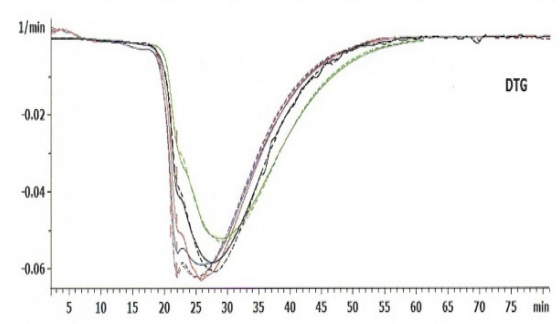

(a)

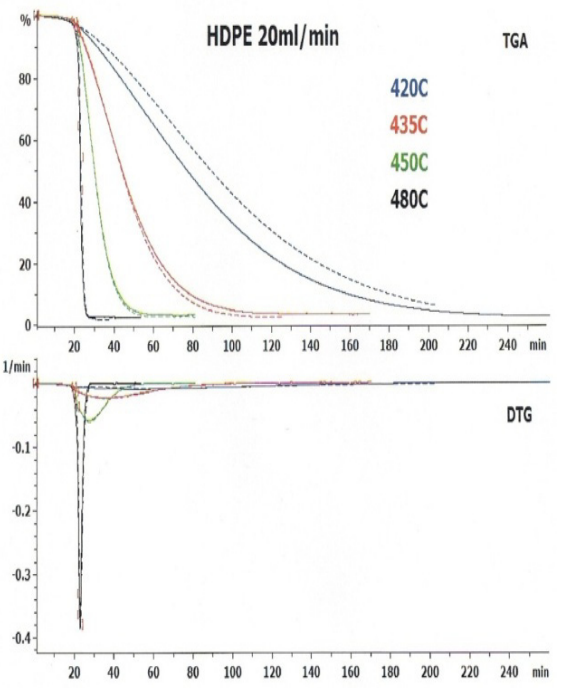

(b)

Figure 2: (a) TGA and DTG analysis of thermal decomposition experiments under pyrolytic conditions at $450^{\circ} \mathrm{C}$ and inert gas discharge ranging of 20,70, 120 and $170 \mathrm{ml} / \mathrm{min}$. (b) TGA and DTG analysis of thermal decomposition experiments under pyrolytic conditions under inert gas discharge of $20 \mathrm{ml} / \mathrm{min}$ at varying experimental temperatures $\left(420,435,450\right.$ and $\left.480^{\circ} \mathrm{C}\right)$. 
There is a strong dependence between the experimental temperature and the decomposition rate. The lowest decomposition rate was measured at $420^{\circ} \mathrm{C}$, and the highest at $480^{\circ} \mathrm{C}$. Table 1 gives the assigned temperature and the measured average maximal decomposition rate.

The rate change corresponds to an exponential low $\left(\mathrm{y}=2 \mathrm{E}-21 \mathrm{e}^{0.0687 \mathrm{X}}\right)$. The activation energy of the decomposition process was calculated using the Arrhenius equation to be $298 \mathrm{KJ} / \mathrm{mol}$; this value is in accordance with data in the literature [9-10].

Table 1: Average maximal decomposition rate at the different experimental temperature.

\begin{tabular}{|c|c|}
\hline $\begin{array}{c}\text { Temperature } \\
\left({ }^{\circ} \mathrm{C}\right)\end{array}$ & $\begin{array}{c}\text { Average maximal decomposition } \\
\text { rate }(\% / \mathrm{min} ; \mathrm{n}=8)\end{array}$ \\
\hline 420 & $0.79 \pm 0.074$ \\
\hline 435 & $2.35 \pm 0.207$ \\
\hline 450 & $6.22 \pm 0.398$ \\
\hline 480 & $49.71 \pm 1.109$ \\
\hline
\end{tabular}

\subsection{Lab scale experiments}

\subsubsection{Pyrolysis experiments}

TGA experiments have verified that the decomposition temperature has a significant effect on the decomposition process. A temperature of $450^{\circ} \mathrm{C}$, at the center of the examined range, was chosen as target temperature of the experiments on the lab-scale system. An inert gas discharge of $20 \mathrm{ml} / \mathrm{min}$ was selected, to increase the decomposition products residence time in the reactor, in order to promote further break-down to shorter hydrocarbon chains.

However, experiments at $450^{\circ} \mathrm{C}$ have yielded only $22 \%$ of gas product at room temperature, whereas $74 \%$ of the product was composed of wax and oil. Thus, an attempt was made to increase the decomposition temperature to $525^{\circ} \mathrm{C}$ and $600^{\circ} \mathrm{C}$, to examine the influence of the higher temperature on the product distribution.

Figure 3 shows the product distribution within the different fractions (e.g. gas at room temperature, low temperature condensates $\left(5^{\circ} \mathrm{C}\right)$, high temperature condensates $\left(180^{\circ} \mathrm{C}\right)$ and char) after a pyrolysis experiment in the lab-scale system.

The temperature increase from $450^{\circ} \mathrm{C}$ to $525^{\circ} \mathrm{C}$ has increased the gas yield, from $22 \%$ to $63 \%$, however, further increase to $600^{\circ} \mathrm{C}$ gave similar results within the experimental error, with no further increase in the gas fraction over the oil and wax.

The char fraction has not varied in the different experiments and ranged between values of $1.4-1.8 \%$. 


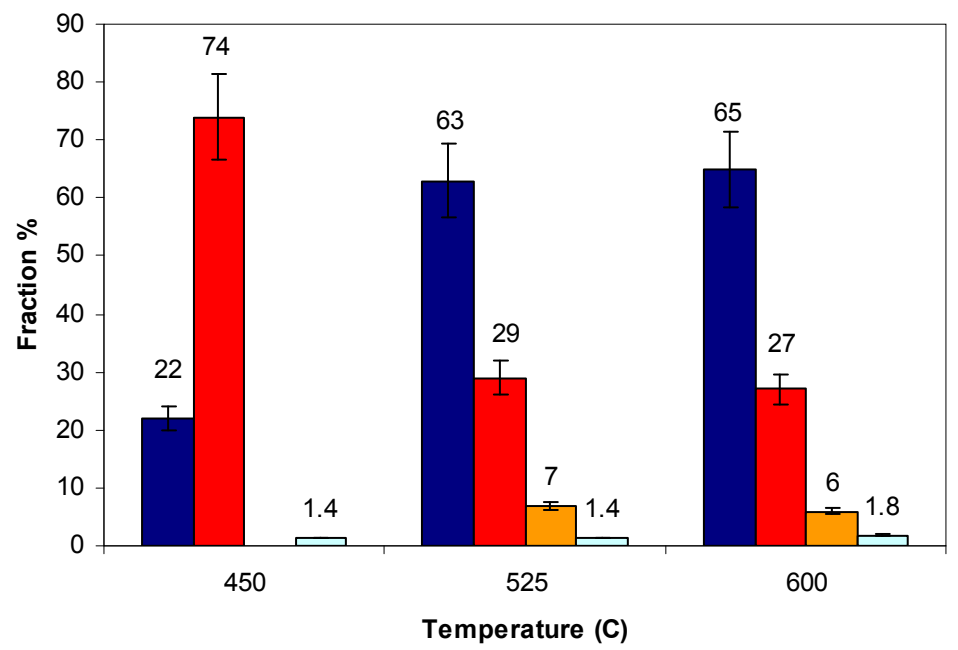

Gas $\square$ Low Temperature condensates $\square$ High Temperature condensates $\square$ Char

Figure 3: The product distribution: room temperature gas, low temperature condensates $\left(5^{\circ} \mathrm{C}\right)$, high temperature condensates $\left(180^{\circ} \mathrm{C}\right)$ and char after pyrolysis experiments in the lab-scale system, for experiments at 450,525 and $600^{\circ} \mathrm{C}$.

\subsubsection{Gasification experiments}

In order to further increase the gas yield in the laboratory scale system, 3, 7 and $12 \%$ oxygen was added to the nitrogen atmosphere, keeping the total gas discharge at $20 \mathrm{ml} / \mathrm{min}$. The temperature chosen for the experiments was $525^{\circ} \mathrm{C}$, as this was the optimized temperature (e.g. lowest temperature and maximum gas yield) in the former experimental step.

Figure 4 shows the product distribution within the different fractions (e.g. gas at room temperature, low temperature condensates $\left(5^{\circ} \mathrm{C}\right)$, high temperature condensates $\left(180^{\circ} \mathrm{C}\right)$ and char) after gasification experiments in the lab-scale system. The results show no significant effect of the oxygen addition at the current conditions. The amount of gas products was between 54 and $61 \%$, with minor increase in the gas product with the increase in the oxygen percent from 3 to $12 \%$. It is interesting to note that none of the experiments showed a gas yield higher than the yield obtained in the pyrolysis experiment at the same temperature $(63 \%)$.

The amount of the high temperature condensate decreased with the increase in the oxygen percent from 19 to $11 \%$, however the amount of the low temperature condensates remained the same within error. The char percentage was similar to the values measured in the pyrolysis experiment within the experimental error. 


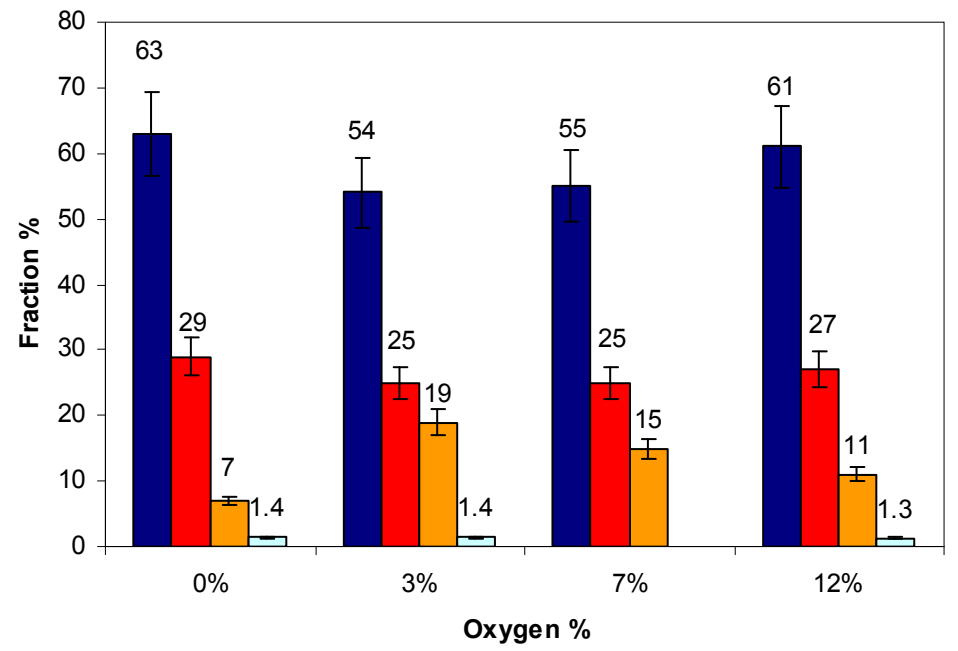

- Gas $\square$ Low Temperature condensates $\square$ High Temperature condensates $\square$ Char

Figure 4: The product distribution: room temperature gas, low temperature condensates $\left(5^{\circ} \mathrm{C}\right)$, high temperature condensates $\left(180^{\circ} \mathrm{C}\right)$ and char after pyrolysis and gasification experiments in the lab-scale system for experiments at $525^{\circ} \mathrm{C}$ with $0,3,7$ and $12 \%$ oxygen.

\section{Discussion and conclusions}

The aim of this study was to maximize the gas yield in the decomposition of HDPE under pyrolytic/gasification conditions. TGA experiments have shown a strong dependence of the HDPE decomposition rate on the applied temperature. The experiments have shown two order of magnitude increases in the decomposition rate, where the lowest decomposition rate was measured at $420^{\circ} \mathrm{C}(0.79 \% / \mathrm{min})$ and the highest decomposition rate was measured at $480^{\circ} \mathrm{C}$ $(49.71 \% / \mathrm{min})$. All TGA experiments show no dependence on the inert gas flow rate. The activation energy calculated is in accordance to reference values [9-10].

However, decomposition experiments in a lab scale system have shown that the decomposition products at $450^{\circ} \mathrm{C}$ are mostly wax and oil products with relatively low gas production. Additional experiments at $525^{\circ} \mathrm{C}$ show significant increase in the gas yield to $63 \%$, but further increase in the experimental temperature to $600^{\circ} \mathrm{C}$ has shown no additional improvement in the products distribution. These results are significantly different to thermal decomposition experimental results in other systems. For example, del Remedio Hernandez et al. [11] have reported HDPE pyrolysis results in pyroprobe and a fluidized bed reactor. The Gas yield in fluidized bed reactor 
experiment at 500 and $600^{\circ} \mathrm{C}$ rose from $15 \%$ to $34 \%$ whereas, in the pyroprobe experiments, it was significantly lower with values of 0.9 to $1.2 \%$ for 500 and $600^{\circ} \mathrm{C}$ respectively. Although for both systems an increase in the gas production was detected with the temperature rise from 500 to $600^{\circ} \mathrm{C}$, the gas yields were significantly lower than the gas yield in the batch reactor used in this study. In another study [12] flash and slow pyrolyis of HDPE were compared. The gas yield rose from 15 to $32 \%$ between 500 and $600^{\circ} \mathrm{C}$ in the flash systems where in the slow system, only $26 \%$ of gas was measured at $700^{\circ} \mathrm{C}$.

The large differences between these examples and the current study, reflects the high sensitivity of the pyrolysis process to the experimental system used and shows that minor differences in the system may cause significant changes in the product. The relatively large gas yield at low temperature in our system arises from the reactor large volume resulting in a long residence time of the hydrocarbon products in the reactor, the calculated residence time, at maximal gas production is 0.7-1.1 min. Kumar and Singh (2011) [13] have shown that in a batch reactor, for very long residence time (up to $760 \mathrm{~min}$ ), very high gas yield (up to $87 \%$ ) was measured at $400^{\circ} \mathrm{C}$. Furthermore, the fact that the reactor in this study is not isothermal and, the temperature at its center is higher by $10 \%$ relative to the reference temperature, exposes the products to higher temperature enabling their breakdown to shorter hydrocarbon chains. The fact that no further increase in gas yield is observed with the temperature increase from 525 to $600^{\circ} \mathrm{C}$, may reflect approaching the maximal gas breakdown ability, since at higher temperatures a transition towards charring and aromatization occurs (e.g. [14]). The fact that the addition of oxygen to the carrier gas flow did not improve the system performance is probably due to the relatively low gas flow rate used $(20 \mathrm{ml} / \mathrm{L})$ relative to the high decomposition gas yield at the peak of the process, thus, becoming a limiting factor and not enabling full gasification of the system. Further experiments should be conducted at higher carrier gas discharge to validate this point.

\section{References}

[1] Demirbas, A., (2004) Pyrolysis of municipal plastic wastes for recovery of gasoline-range hydrocarbons, Journal of Analytical and Applied Pyrolysis, Volume 72, 1, 97-102.

[2] Ray, R. \& Thorpe, R. B. (2007) A Comparison of Gasification with Pyrolysis for the Recycling of Plastic Containing Wastes. International Journal of Chemical Reactor Engineering 5: A85.

[3] de Marco, I., Caballero, B. M., Chomon, M. J, Laresgoiti, M. F., Torres, A., Fernandez, G. \& Arnaiz, S. (2008) Pyrolysis of electrical and electronic wastes. Journal of Analytical and Applied Pyrolysis, 82, 179-183.

[4] Pytlar, T. S. (2010) Status of existing biomass gasification and pyrolysis facilities in North America. In: Proceedings of the 18th Annual North American Waste-to-Energy Conference, NAWTEC18. 
[5] Review of technology for the gasification of biomass and wastes (2009), report by NNFCC project 09/008, E4tech.

[6] Technology evaluation and economic analysis of waste tire pyrolysis, gasification, and liquefaction (2006), report by the University of California Riverside, Integrated waste management board, pp. 97.

[7] Application of thermal technologies for processing of radioactive waste (2007), report by the International Atomic Energy Agency, IAEA-TECDOC-1527, pp.81.

[8] Sinfrônio, F. S. M., Santos, J. C. O. Pereira, L. G., Souza, A. G., Marta M., Conceição, V. J., Fernandes, Jr. \& Fonseca, V. M. (2005) Kinetic of thermal degradation of low-density and high-density polyethylene by non-isothermal thermogravimetry, Journal of Thermal Analysis and Calorimetry, Vol 79, 2, pp. 393-399.

[9] Gugumus, F. (2000) Thermolysis of polyethylene hydroperoxides in the melt: 1. Experimental kinetics of hydroperoxide decomposition. Energy Sources, Part A, 30:385-391, 2008.

[10] Kayacan, I. \& Dogan O. M. (2008) Pyrolysis of Low and High Density Polyethylene. Part I: Non-isothermal Pyrolysis Kinetics. Polymer Degradation and Stability, Vol 69, Issue $123-34$.

[11] del Remedio Hernandez, M., Gomez, A., Garcia, A. N., Javier A. \& Marcilla, A. (2007) Effect of the temperature in the nature and extension of the primary and secondary reactions in the thermal and HZSM-5 catalytic pyrolysis of HDPE. Applied Catalysis A: General 317 (2007) 183-194.

[12] Marcilla A., del Remedio Hernandez M. \& Garcia A. N. (2007) Study of the polymer-catalyst contact effectivity and the heating rate influence on the HDPE pyrolysis. Journal of Analytical and Applied Pyrolysis, 79, 424-432.

[13] Kumar, S. \& Singh, R. K. (2011) Recovery of hydrocarbon liquid from waste high density polyethylene thermal pyrolysis. Brazilian Journal of Chemical Engineering, 28(04), 659-667.

[14] Font, R., Aracil, I., Fullana, A., Martın-Gullo'n, I. \& Conesa, J. A. (2003) Semivolatile compounds in pyrolysis of polyethylene. Journal of Analytical and Applied Pyrolysis, 68-69, 599-611. 